MR JOSE SANCHEZ-MORENO (Orcid ID : 0000-0003-1520-093X)

DR VICENT BALANZÁ-MARTÍNEZ (Orcid ID : 0000-0001-7772-7396)

PROFESSOR MARIA PAZ GARCIA-PORTILLA (Orcid ID : 0000-0003-3643-1622)

DR ANABEL MARTINEZ-ARAN (Orcid ID : 0000-0002-0623-6263)

MISS CARLA TORRENT (Orcid ID : 0000-0003-0335-582X)

PROFESSOR EDUARD VIETA (Orcid ID : 0000-0002-0548-0053)

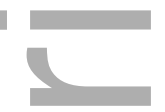

Article type : Original Article

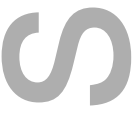

\title{
FACTORS ASSOCIATED WITH POOR FUNCTIONAL OUTCOME IN BIPOLAR DISORDER: SOCIODEMOGRAPHIC, CLINICAL AND NEUROCOGNITIVE VARIABLES
}

Jose Sanchez-Moreno $^{\mathrm{a}}$, Caterina del Mar Bonnin ${ }^{\mathrm{a} *}$, Ana González-Pinto ${ }^{\mathrm{b}}$, Benedikt L. Amann $^{\mathrm{c}}$, Brisa Soléa ${ }^{\mathrm{a}}$, Vicent Balanzá-Martinez ${ }^{\mathrm{d}, \mathrm{e}}$, Celso Arango $^{\mathrm{f}}$, Esther Jiménez ${ }^{\mathrm{a}}$, Rafael Tabarés-Seisdedos ${ }^{\mathrm{d}}$, M. Paz Garcia-Portilla ${ }^{\mathrm{g}}$, Angela Ibáñez ${ }^{\mathrm{h}}$, Jose Manuel Crespo $^{\mathrm{i}}$, Jose Luis Ayuso-Mateos ${ }^{\mathrm{j}}$, Anabel Martinez-Aran ${ }^{\mathrm{a}^{*}}$, Carla Torrent ${ }^{\mathrm{a}}$, Eduard Vieta $^{\mathrm{a}}$ CIBERSAM Functional Remediation Group ${ }^{1}$.

a Barcelona Bipolar Disorders Program, Institute of Neurosciences, University of Barcelona, Hospital Clinic of Barcelona, IDIBAPS, CIBERSAM, Barcelona, Catalonia, Spain

b Álava University Hospital, CIBERSAM, University of the Basque Country, BIOARABA, Vitoria, Spain.

${ }^{\mathbf{c}}$ Centre Fòrum Research Unit, Institute of Neuropsychiatry and Addictions, Parc de Salut Mar, Institut Hospital del Mar d'Investigacions Mèdiques, Department of Psychiatry, Autonomous University of Barcelona, Parc de Salut Mar, CIBERSAM, Barcelona, Spain

This is the author manuscript accepted for publication and has undergone full peer review but has not been through the copyediting, typesetting, pagination and proofreading process, which may lead to differences between this version and the Version of Record. Please cite this article as doi: $10.1111 /$ acps.12894

This article is protected by copyright. All rights reserved 
${ }^{\mathbf{d}}$ Department of Medicine, University of Valencia, CIBERSAM, INCLIVA, Valencia, Spain.

${ }^{\mathbf{e}}$ Department of Psychiatry, La Fe University and Polytechnic Hospital, Valencia, Spain.

${ }^{\mathbf{f}}$ Child and Adolescent Psychiatry Department, Hospital Universitario Gregorio

Marañón School of Medicine, Universidad Complutense, IiSGM, CIBERSAM, Madrid, Spain.

${ }^{\mathrm{g}}$ Department of Psychiatry, School of Medicine, University of Oviedo, CIBERSAM Instituto de Neurociencias del Principado de Asturias, INEUROPA. Servicio de Salud del Principado de Asturias (SESPA), Oviedo, Spain.

${ }^{\mathbf{h}}$ Department of Psychiatry, Hospital Universitario Ramón y Cajal, Universidad de Alcalá, IRYCIS, CIBERSAM, Madrid, Spain.

i Department of Psychiatry, University Hospital of Bellvitge, Bellvitge Biomedical Research Institute (IDIBELL), CIBERSAM, Barcelona, Spain.

${ }^{j}$ Department of Psychiatry, Universidad Autónoma de Madrid, IIS-IP, CIBERSAM, Madrid, Spain

Corresponding author at: Bipolar Disorder Program. Clinical Institute of Neuroscience. Hospital Clinic of Barcelona, Villarroel, 170. 08036 Barcelona, Spain. Tel.: +34 9322754 01; fax: +3493227 9228. E-mail addresses: amartiar@ clinic.cat (A. Martinez-Aran); cbonnin@ clinic.cat (CM Bonnin), * Co-corresponding authors.

${ }^{1}$ The CIBERSAM Functional Remediation Group consists of: Analucía Alegría, Susana Al-Halabi, Silvia Alonso-Lana, Celia Anaya, Purificación López, Julio Bobes, Guadalupe Chiclana, Esther Cerrillo, Patricia Correa, Núria Custal, Patricia Fernández, Sainza García, Inmaculada Fuentes-Durá, Gonzalo Galván, Itxaso González-Ortega, Ana Ibáñez, Sandra Isella, Ramon Landín-Romero, José Manuel Menchón, Jessica Merchan-Naranjo, Jordi Ortiz-Gil, Isabella Pacchiarotti, Raquel Reyes, Marta RapadoCastro, Maria Reinares, José Maria Rodao, Pilar A Saiz, Bárbara Segura, Gabriel SelvaVera, Jerónimo Saiz-Ruiz, Virginia Soria, Iñaki Zorrilla, Jesús Valle, Elia Valls, Cristina Varo.

\section{Abstract}

OBJECTIVE:The current investigation aimed at studying the sociodemographic, clinical and neuropsychological variables related to functional outcome in a sample of 
euthymic patients with bipolar disorder(BD) presenting moderate-severe levels of functional impairment.

METHODS:Two-hundred and thirty-nine participants with BD disorders and with Functioning Assessement Short Test(FAST) scores equal or above 18 were administered a clinical and diagnostic interview, and the administration of mood measure scales and a comprehensive neuropsychological battery. Analyses involved preliminary Pearson bivariate correlations to identify sociodemographic and clinical variables associated to the FAST total score. Regarding neuropsychological variables, a Principal Component Analysis(PCA) was performed in order to group the variables in orthogonal factors. Finally, a hierarchical multiple regression was run.

RESULTS:The best fitting model for the variables associated with functioning were a linear combination of gender, age, estimated IQ, Hamilton Depression Rating Scale (HAM-D), number of previous manic episodes, factor 1 and factor 2 extracted from the PCA. The model, including all these previous variables explained up to $29.4 \%$ of the observed variance.

CONCLUSIONS:male gender, older age, lower premorbid IQ, subdepressive symptoms, higher number of manic episodes and lower performance in verbal memory, working memory, verbal fluency and processing speed were associated with lower funcioning in patients with BD.

\section{KEY WORDS: bipolar disorder, functional impairment, neurocognition, depressive symptoms.}

\section{Significant Outcomes}

- This is the first study to examine potential sociodemographic, clinical and neurocognitive factors associated with functioning in a homogenous sample of patients with BD with marked functional impairment.

- The identification of the variables associated with severe functional impairment, such as manic relapses, subsyndromal depressive symptoms and neurocognitive impairment, may stimulate further treatment trials to restore functional outcome. 
- Early interventions including prevention of manic relapses through psychoeducation and cognitive enhancement by means of functional and cognitive remediation, require further research in order to reduce disability.

\section{Limitations}

- The cross-sectional nature of this study does not allow drawing precise conclusions regarding contributing pathways involved in psychosocial functioning in Bipolar Disorders.

- Other variables not studied, as medical comorbidity, or environmental factors could also explain functionality. In the current study, pharmacological treatment was not controlled for, so that we cannot rule out its potential impact on functioning and cognitive outcomes. Introduction

Bipolar disorder (BD) is one of the leading causes of disability worldwide and implies a tremendous burden on patients and the healthcare system $(1,2)$. It is well-known that patients with clinical remission present difficulties in reaching full functional recovery despite having achieved syndromal recovery (3). Functional recovery in role expectation at home, functioning in school or interpersonal relationships might take longer than syndromal recovery since they involve different and more complex processes in the real world. Hence, it is not surprising that the gap between clinical remission and functional outcome comprise many factors that go beyond "being well". It includes variables related to the course of the illness/illness severity, genetics, comorbidities, and cognitive impairment $(4,5)$. Probably, one of the most consistent results across different studies is the role of subthreshold symptoms on functioning (610). Results from research with regards to other clinical and neuropsychological variables are still inconsistent. These inconsistencies could be due to differences in methodology of studies, for instance, since some of them are longitudinal (9-12), while some others are cross-sectional $(8,13,7)$. Another critical factor is the outcome measure which is in some studies the Global Assessment Functioning (GAF) (9, 10 14), whereas in others the Multidimensional Scale of Independent Functioning (MSIF) (9) or the Functioning Assessment Short Test (FAST) (12-14).

Finally, the sample composition of studies also differs, with some including firstepisode patients $(9,16-18)$, bipolar I type patients $(10)$, or mixed samples $(12,7)$. It is likely that the latter studies include mixed patients with and without functional 
impairment, which may also generate different results, with discrepancies among findings.

A homogenous group could help to disentangle the predictors associated to functional impairment in BD. In this line, it is probably useful to differentiate patients with no or mild impairment (high functioning group) from those patients with moderate to severe impairment (low functioning group). The present report aims at studying the sociodemographic, clinical and neuropsychological factors associated to low functional outcome in a homogeneous sample of patients with BD.

\section{Method}

Participants

Data from 239 remitted BD patients was pooled from a previous multicenter study including different centers across Spain. The original study was performed between 2009 and 2011. It was a randomized, rater-blind outpatient trial including three parallel arms (1:1:1) in order to evaluate the efficacy of functional remediation as an add-on therapy compared to psychoeducation and treatment as usual in bipolar disorder. For the present study the baseline variables of 239 patients were analyzed only to avoid the confounding effect of the subsequent interventions. For all details of the original study about the efficacy of the therapies see: Torrent et al., 2013 (19); Bonnin et al., 2016 (20). The trial was registered at Clinicaltrials.gov (identification number NCT01370668).

Inclusion criteria were patients aged between 18 and 55 years and with a diagnosis of bipolar I or II disorder according to DSM-IV-TR criteria. Patients were required to have had 3 months of clinical remission before entering the randomization phase. Euthymia was defined as Young Mania Rating Scale $\leq 6$ (YMRS) $(21,22)$ and a Hamilton Depression Rating Scale $\leq 8$ (HAM-D) $(23,24)$. All patients had to show a moderate to severe degree of functional impairment, as score above or equal 18 was required on the FAST (25)

Assessments

Clinical Assessment

All participants went through a clinical interview based on the Structured Clinical Interview for DSM-IV to confirm diagnosis of BD. Clinical and sociodemographic data 
included age, gender, education level, diagnosis, number and type of episodes, illness duration, age at first hospitalization, age at illness onset, history of psychosis, family psychiatric history and comorbidities.

\section{Functional Assessment}

Psychosocial functioning was evaluated by means of the FAST (25). This scale is an interviewer-administered instrument developed to assess the main difficulties in daily life that patients with BD may experience. The FAST is a reliable instrument, easy to apply and requires short time to administer. It comprises 24 items that allow for evaluation of functioning in 6 specific different areas: autonomy, occupational functioning, cognitive functioning, interpersonal relationships, financial issues and leisure time. Each item is rated using a 4-point scale, that ranges from 0 (no difficulty) to 3 (severe difficulty). The global score results from the addition of all the items of the scale. The FAST total score can range from 0 to 72 and higher scores indicate greater disability, the cut-off score indicating functional impairment was established in 11 or higher scores in the original study of validation (25).

\section{Neuropsychological Assessment}

Patients were tested with a neuropsychological battery exploring different cognitive domains: processing speed, working memory, executive functions, verbal learning/memory, visual memory, and attention. For a more detailed description of the neuropsychological battery see Torrent et al., 2013 (19).

\section{Data analysis}

Descriptive analyses of sociodemographic variables including age, gender and education level were conducted. Regarding the clinical variables, family psychiatric history, lifetime psychotic symptoms, lifetime rapid cycling, age of onset, number and type of episodes were also analyzed. Categorical variables were analyzed by their frequencies and percentages; quantitative variables were described by their means and standard deviations.

Regarding the neuropsychological variables, a Principal Component Analysis (PCA) followed by an orthogonal rotation (varimax) was used to accomplish two purposes: first, to reduce the number of neurocognitive variables to a smaller number of components, each of them consisted of several correlated variables and second, to 
ensure the creation of uncorrelated factors to be further introduced on a hierarchical regression model.

After the PCA, preliminary Pearson bivariate correlations of the variables associated to the FAST total score were run. They included the sociodemographic and the clinical variables and the factors derived from the PCA. Only those variables with a p value $\leq 0.05$ were then entered in the regression model. Besides these variables, the authors considered to introduce other relevant factors that have been identified in literature to influence psychosocial outcome such as gender, diagnosis subtype (5) and number of previous depressive episodes (26).

The hierarehical multiple regression evaluated the contribution of the clinical, sociodemographic and neuropsychological variables to the functional outcome. Sociodemographic variables were included at step 1, then the clinical variables at step 2 and finally, all the neurocognitive factors at step 3. Tests for multicollinearity in all variables were run. Variables were required not to exceed variance inflation factor (VIF) values above 10. Before running the regression model, tests for multicollinearity indicated very low levels of multicollinearity in the in the model. In fact, none of the variance inflation factor (VIF) values exceeded 10. Moreover, outliers were explored by applying the casewise diagnosis (more than 3 standard deviations below or above mean). All statistical analyses were conducted using IBM SPPS Statistics version 23.0. Statistical significance was set at $\mathrm{p}<0.05$.

\section{Results}

Sociodemographic and clinical characteristics of the sample Mean age for the total sample $(\mathrm{n}=239)$ was 40.1 years old $(\mathrm{SD}=8.8)$. Women were slightly more prevalent than men $(n=138 ; 57.7 \%)$. Most of the participants were diagnosed with BD type $\mathrm{I}(\mathrm{n}=179 ; 77.2 \%)$. As shown by the FAST total score (mean=29.9; $\mathrm{SD}=9.9$ ), the sample presented moderate to severe levels of functional impairment. Finally, the mean for illness duration was 14.6 years. See table 1 for detailed information regarding all the variables.

$<<$ Insert table 1 about here>> 


\section{Principal Components Analysis}

Examination of the Kaiser-Meyer-Olkin (KMO) measure of sampling adequacy suggested that the sample was factorable, since the value was $>0.5(\mathrm{KMO}=0.85)$. In the same line, Barlett Sphericity test was significant ( $\mathrm{Chi}=2132.96 ; \mathrm{df}=120 ; \mathrm{p}<0.001)$. The visual examination of the scree plot revealed 4 factors to retain, since four eigenvalues exceeded 1. The first four components in the PCA explained up to $69.9 \%$ of the data variance. The components of the PCA are shown in table 2 along with the variables that loaded the highest (i.e: had the highest association) with each component.

As shown in table 2, loadings of the five cognitive scores in Factor 1 were from verbal memory, specifically, the California Verbal Learning Test (CVLT) including short and delayed recall and the total words recalled, thus we named this factor "verbal memory". Factor 2 received high loadings from Processing Speed IQ; psychomotor speed (TMTA,B); Working-Memory IQ and verbal fluency (animal naming and phonemic fluency). Therefore, we labeled this factor as "processing speed, working memory and fluencies". Factor 3 received loadings from Wisconsin Card Sorting Test (WCST) categories, WCST perseverative errors and Stroop Color Word Test (SCWT) interference index, this factor was labeled "frontal-executive". Finally, factor 4 included two variables assessing logical memory and it was tagged "logical memory". See table 2 for detailed information.
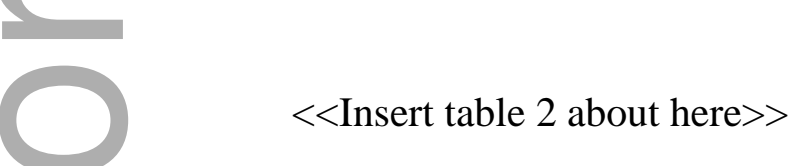

\section{Pearson correlations}

Several variables were found to correlate with the FAST total score: HAM-D total score $(r=0.304 ; p<0.001)$; age $(r=0.190 ; p=0.03)$; years of education $(r=-0.214 ; p=0.001)$; years of illness $(r=-0.233 ; p=0.04)$, number of previous manic episodes $(r=0.186$; $\mathrm{p}=0.004)$, and estimated IQ ( $\mathrm{r}=-0.223 ; \mathrm{p}=0.001)$. Factors from the PCA also correlated significantly with the FAST total score: Factor $1(r=-0.218$; $p=0.001)$; Factor 2 (r=$0.240 ; \mathrm{p}<0.001)$, Factor $3(\mathrm{r}=-0.156 ; \mathrm{p}=0.022)$ and Factor $4(\mathrm{r}=-0.17 ; \mathrm{p}=0.01)$.

\section{Hierarchical Regression Model}


To test the hypothesis that functional outcome was associated to sociodemographic, clinical and neuropsychological variables, a hierarchical multiple regression analysis was performed. The variables that correlated significantly with functional outcome were introduced in the regression model as independent variables. They included the significant $(\mathrm{p} \leq 0.05)$ Pearson correlations (clinical and sociodemographic variables), the significant neurocognitive variables derived from the PCA and the variables already identified in the literature, which are described in the methods section. Besides these mentioned variables, the authors considered to introduce other relevant variables that have been identified in literature to influence psychosocial outcome such as gender, diagnosis subtype (5) and number of previous depressive episodes (26). Before running the regression model, tests for multicollinearity indicated very low levels of multicollinerity in the in the model. In fact. Regarding the tests for multicollinearity, none of the VIF values exceeded 10. Results of the regression analysis provided that the best fitting model for the variables associated to functional outcome were a linear combination of gender, age, estimated IQ, HAM-D total score, number of previous manic episodes, factor 1 (verbal memory) and factor 2 (processing speed, working memory and fluencies). The model, including all these previous mentioned variables explained up to $29.4 \%$ of the variance observed in data $\left(\mathrm{R}^{2}=0.294 ; \mathrm{F}_{(13,105)}=6.14 ; \mathrm{p}<0.001\right)$. See table 3 for detailed information.

$$
<<\text { Insert table } 3 \text { about here >> }
$$

\section{Discussion}

This study aimed at identifying which variables were most associated to functional outcome in a sample of euthymic bipolar patients with poor functioning. After controlling for clinical and sociodemographic variables, functional impairment was partly accounted by neurocognitive variables. To the best of our knowledge, this is the first study to examine potential sociodemographic, clinical and neurocognitive factors associated with functioning in a homogenous sample of patients with BD with marked functional impairment.

\section{The role of sociodemographic factors}


Sociodemographic variables associated to poorer outcome included male gender, older age, and lower estimated IQ. The former two variables have already been described as factors influencing functioning in previous studies both in cross-sectional and longitudinal studies $(27,7,28)$. Actually, a recent study $(7)$ and others $(29,30)$ found that age and gender together with other non-modifiable factors (such as diagnosis and illness duration) were variables that could predict impaired functioning in a sample of euthymic patients with bipolar disorder. In this sense, age may modify individual patients' perceptions of their capacity/ability to perform daily activities, being the older patients more inclined to perceive themselves as more impaired and to report more difficulties in their day to day functioning. There is also one study pointing out that the impact of increasing age on a poorer functioning is regardless of the diagnosis (schizophrenia, bipolar disorder or schizoaffective disorder) (31).

Even though we controlled both for educational level and estimated IQ, only the latter variable remained significant in the final model. IQ was also found as a predictive factor in a previous study on functional outcome in BD (32). Estimated IQ is thought to be one of the main contributors of cognitive reserve. Patients with higher cognitive reserve present compensation mechanisms that are supposed to be more effective when compared to patients with lower cognitive reserve. These mechanisms allow a better social, occupational and cognitive outcome, as it has been shown in recent literature (13, 33-35). Though, both years of education and estimated IQ correlated with functioning, in the present study, only estimated IQ was significant, and the results are in line with the aforementioned studies, suggesting that those patients with higher estimated IQ would present better functional outcome. It is also worth mentioning that some studies haven't found this association, for instance Leeson et al., (36) suggested that social adaptation would not be related to premorbid IQ but of current intelligent abilities.

\section{The role of clinical factors}

The number of previous episodes is a variable that has been traditionally reported to influence functional outcome. However, to date, there has been no agreement whether it is the previous manic or the previous depressive episodes that have more deleterious effect on psychosocial functioning. Several studies point at a negative effect of manic episodes specifically on work functioning $(37,38,39)$, while others noted that the burden of previous depressive episodes would be negatively impacting on job performance $(28,40)$. When it comes to general functioning, results are contradictory as 
well. Some studies point out to the role of previous depressive episodes (26, 42-44), while some others report the negative effect of manic episodes $(45,27,46,47)$. In the present study, we found an effect of previous manic episodes but not a significant impact from previous depressive episodes. Currently, it is still unclear the role of the type of episodes on functioning, although more episodes may cause long-lasting changes in different brain pathways that may impact global functioning in patients with BD $(48,49)$. Another possible explanation is that patients with multiple episodes, especially manic episodes, are more prone to neurocognitive impairment that may in turn worsen psychosocial functioning $(50,51,52)$.

Subthreshold depressive symptoms seem to be one of the central factors involved in functional impairment, since it is a variable that consistently appears in literature (53, $12,32,54,18,7,55)$. Subthreshold symptoms are one of the main contributors for relapse and functional impairment $(56,46)$ representing a challenge in the treatment of BD. It is known that even low levels of subthreshold depressive symptoms can impact on functional outcome $(12,39,57)$. However some studies suggest that the relationship between subthreshold symptoms and functional outcome should be considered as circular: patients with subthreshold symptoms might be prone to poorer functional outcome, but patients with more functional impairment may be also more likely to present greater mood instability $(58,56,46)$. Moreover, the present results seem to indicate that subthreshold symptoms are more related to functional outcome rather than diagnosis subtype, which is in line with previous findings $(7,59)$. This means that subthreshold depressive symptoms are equally disabling for both Bipolar I and II subtypes. Despite the burden of these symptoms, its treatment is still immature: neither pharmacological nor psychological interventions have been developed so far to specifically target them. Some evidence of a positive effect on subsyndromal symptoms derives from cognitive remediation (60), functional remediation in a subsample of patients with bipolar II disorder (54) and Eye Movement Desensitization therapy in traumatized patients with BD (61). However, only one of the above-mentioned interventions ( 60 focused a part of the intervention to target subthreshold symptoms. If the circular relationship between subsyndromal and functional outcome is certain, it would make sense to focus the interventions on both domains in order to improve them $(46,62)$. 
Coupled with the findings above-mentioned, it seems that in BD various connections exist between subsyndromal depressive symptoms, psychosocial functioning and neurocognitive performance. Understanding these linkages may be important for clinical considerations including illness management, treatment and rehabilitation.

\section{The role of neurocognitive factors}

Neurocognitive impairment together with subthreshold depressive symptoms might be the two key factors related to the functional impairment observed in $\operatorname{BD}(5,46)$. Nevertheless, to date, it is difficult to ascertain which neuropsychological domain (verbal memory, executive functions, psychomotor speed, working memory, etc) mostly influences on functional impairment. For this reason, PCA was carried out in our study in order to reduce the number of neurocognitive variables to a smaller number of components, each of them consisted of several correlated variables and secondly, to ensure the production of uncorrelated factors to be further introduced on the hierarchical regression model. In the present study, we found an effect of verbal memory, , processing speed, verbal fluency and working memory, which represents an implication of several neurocognitive domains. Nevertheless, this finding is not surprising since this non-specific profile might be more associated to patients presenting poor functioning. It has been shown in previous reports that global neurocognitive impairment in BD patients is associated to more functional disabilities than those who were cognitively intact $(63,64)$. In the same line, a prospective study found that a global composite cognitive score (CNSC) at baseline could predict changes in functioning at one-year follow-up, measured by means of GAF (10). However, that sample was comprised only of BD type I patients and the mean scores of the GAF were 70, which would correspond with a FAST total score around 15-18 (25).

Cognitive deficits appear to be a strong limiting factor of everyday functioning not only in late stages of illness but also in early phases $(8,17,51)$. Some approaches have been done in order to improve functioning and neurocognition in BD with some encouraging results, including both psychological and pharmacological interventions $(60,19,20,62$, $65,66,67,68,69)$ and another one with negative findings (70). The treatment of neurocognitive impairment is still an area of development and innovation and, maybe, different treatments might be required depending on the stage of the illness $(34,71)$. 
Among the limitations of the study, it should be noted its cross-sectional nature which does not allow drawing precise conclusions regarding contributing pathways involved in psychosocial functioning in BD. Therefore, it is not possible to draw final conclusions on predictors or mediators of functional impairment. In the same line, the factors analyzed explain almost one third of the variance. Other factors not studied, as medical comorbidity, or use of drugs could explain also functionality. On the other hand, the inclusion of a homogenous sample regarding the level of functioning helps identifying best those factors related to functional impairment. A further limitation might include the fact that the results of this work were not the primary objective of the RCT (19). A follow-up of possible variables acting on functioning was not possible as $75 \%$ of the sample received, after baseline, different psychological treatment that had an impact on functional outcome. Finally, in the current study, pharmacological treatment was not controlled for, whereas we cannot rule out its potential impact on functioning and cognitive outcomes.

\section{Conclusions}

Although previous limitations warrant attention, the results of the present study are relevant from a clinical perspective. Patients with $\mathrm{BD}$ presenting significant functional impairment (34) support the relevance of finding effective ways to improve those modifiable variables, such as neurocognitive impairment, number of manic episodes and subthreshold depressive symptoms. Some other non-modifiable variables that have also been identified such as male gender, older age, lower estimated premorbid IQ should be taken into account in order to enhance cognitive reserve or promote interventions in earlier stages of the illness. The identification of the variables associated with severe functional impairment, such as manic relapses, subsyndromal depressive symptoms and neurocognitive impairment, including verbal memory, working memory, verbal fluency and processing speed, may stimulate further treatment trials to restore functional outcome (72). In this regard, prevention of manic relapses through psychoeducation and cognitive enhancement by means of functional and cognitive remediation, for instance, require further research in order to reduce disability (73). Early detection and early intervention in subjects at high risk and first-episode patients (74) appears paramount in order to tackle on the variables that may eventually lead into poor psychosocial functioning.

\section{Conflict of interest}


Dr. Vieta has received grants and served as consultant, advisor or CME speaker for the following entities: AB-Biotics, Actavis, Allergan, AstraZeneca, Bristol-Myers

Squibb, Ferrer, Forest Research Institute, Gedeon Richter, Glaxo-Smith-Kline, Janssen, Lundbeck, Otsuka, Pfizer, Roche, Sanofi-Aventis, Servier, Shire, Sunovion,

Takeda, Telefónica, the Brain and Behaviour Foundation, the Spanish Ministry of Science and Innovation (CIBERSAM), the Seventh European Framework Programme (ENBREC), and the Stanley Medical Research Institute.

Dr. Martinez-Aran has served as speaker or advisor for the following companies:

Bristol-Myers Squibb, Otsuka, Lundbeck and Pfizer

Dr. BL Amann has served as speaker for Janssen, Lundbeck and Otsuka.

Dr. Balanza-Martinez has received grants and has served as a consultant, advisor or Continuing Medical Education (CME) speaker over the last 4 years for the following entities: Angelini Spain; Angelini Portugal; Bristol-Myers-Squibb; Ferrer; Janssen; Juste; Lundbeck; Nutrición Médica; and Otsuka.

Dr. Arango has been a consultant to or has received honoraria or grants from Acadia, Abbot, AMGEN, AstraZeneca, Bristol-Myers Squibb, Caja Navarra, CIBERSAM, Fundación Alicia Koplowiths, Forum, Instituto de Salud Carlos III, Gedeon Richter, Janssen Cilag, Lundbeck, Merck, Ministerio de Ciencia e Innovación, Ministerio de Sanidad, Ministerio de Economía y Competitividad, Mutua Madrileña, Otsuka, Pfizer, Roche, Servier, Shire, Schering Plough, Sumitomo Dainippon Pharma, Sunovio and Takeda.

Dr. González-Pinto has received grants and served as consultant, advisor or CME speaker for the following entities: Eli Lilly, Janssen-Cilag, Lundbeck, Otsuka, Pfizer, , Sanofi-Aventis, Ferrer, the Spanish Ministry of Science and Innovation (CIBERSAM), and the Basque Government.

Dr. Ibáñez has received grants and served as speaker or advisor from Bristol-Myers Squibb, CIBERSAM, Ferrer, Instituto de Salud Carlos III, Lundbeck, Ministerio de Economía, Industria y Competitividad, Otsuka Pharmaceutical SA, and Servier. Maria Paz Garcia-Portilla has been a consultant to and/or has received honoraria/grants from Alianza Otsuka-Lundbeck, CIBERSAM, European Comission, Instituto de Salud Carlos III, Janssen-Cilag, Lilly, Lundbeck, Otsuka, Pfizer, Servier, Roche, and Rovi. The other authors report no financial relationships with commercial interests.

\section{Acknowledgments}


The authors thank the support of the Spanish Ministry of Economy, Industry and Competitiveness, Instituto de Salud Carlos III, CIBERSAM, the Secretaria d'Universitats i Recerca del Departament d'Economia i Coneixement (2017 SGR 1365) and the CERCA Programme / Generalitat de Catalunya.. Dr. Anabel Martinez-Aran's project is supported, in part, by a 2013 NARSAD, Independent Investigator Grant from the Brain \& Behavior Research Foundation. Dr Torrent's project is also supported in part by a 2014 NARSAD, Independent Investigator Grant from the Brain \& Behavior Research Foundation (grant number 22039). Dr. Amann received also a NARSAD Independent Investigator Award (24397) from the Brain \& Behavior Research Foundation. Dr. Bonnín would like to thank the Departament de Salut de la Generalitat de Catalunya with PERIS grant (SLT002/16/00331).

\section{Funding}

This work was supported by grants from the Spanish Ministry of Economy, Industry and Competitiveness grant numbers (PI080180, PI08/90825, PI08/90327, PI08/90675, PI08/90224, PI08/90654, PI08/90189, PI08/90916, PI08/ 90416, PI08/90094, PI11/00637, PI12/00912, PI15/00330, PI15/00283) PN 2008-2011, Instituto de Salud Carlos III, Subdirección General de Evaluación y Fomento de la Investigación; Fondo Europeo de Desarrollo Regional. Unión Europea, "Una manera de hacer Europa"; CIBERSAM; and the Comissionat per a Universitats i Recerca del DIUE de la Generalitat de Catalunya (2017 SGR 1365to the Bipolar Disorders Group).

\section{References}

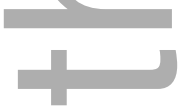

1. Catalá-López F, Gènova-Maleras R, Vieta E, Tabarés-Seisdedos R. The increasing burden of mental and neurological disorders. Eur Neuropsychopharmacol. 2013 Nov;23(11):1337-9

2. GBD 2016 DALYs and HALE Collaborators. Global, regional, and national disability-adjusted life-years (DALYs) for 333 diseases and injuries and healthy life expectancy (HALE) for 195 countries and territories, 1990-2016: a systematic analysis for the Global Burden of Disease Study 2016. Lancet. 2017 Sep 
3. Grande I, Berk M, Birmaher B, Vieta E. Bipolar disorder. Lancet. 2016 Apr 9;387(10027):1561-72.

4. Levy B, Manove E, Weiss RD. Recovery of cognitive functioning in patients with co-occurring bipolar disorder and alcohol dependence during early remission from an acute mood episode. Ann Clin Psychiatry. 2012 May;24(2):143-54.

5. Sanchez-Moreno J, Martinez-Aran A, Tabarés-Seisdedos R, Torrent C, Vieta E, Ayuso-Mateos JL. Functioning and disability in bipolar disorder: an extensive review. Psychother Psychosom. 2009;78(5):285-97

6. Bonnin CM, Sanchez-Moreno J, Martinez-Arán A, Solé B, Reinares M, Rosa AR, Goikolea JM, Benabarre A, Ayuso-Mateos JL, Ferrer M, Vieta E, Torrent C.

Subthreshold symptoms in bipolar disorder: impact on neurocognition, quality of life and disability. J Affect Disord. 2012 Feb;136(3):650-9

7. Murru A, Pacchiarotti I, Verdolini N, Reinares M, Torrent C, Geoffroy PA, Bellivier F, Llorca PM, Vieta E, Samalin L. Modifiable and non-modifiable factors associated with functional impairment during the inter-episodic periods of bipolar disorder. Eurr Arch Psychiatry Clin Neurosci. 2017 May 22. doi: 10.1007/s00406017-0811-0. [Epub ahead of print]

8. Martinez-Aran A, Vieta E, Torrent C, Sanchez-Moreno J, Goikolea JM, Salamero M, Malhi GS, Gonzalez-Pinto A, Daban C, Alvarez-Grandi S, Fountoulakis K, Kaprinis G, Tabares-Seisdedos R, Ayuso-Mateos JL. Functional outcome in bipolar disorder: the role of clinical and cognitive factors. Bipolar Disord. 2007 FebMar;9(1-2):103-13.

9. Torres IJ, DeFreitas VG, DeFreitas CM, Kauer-Sant'Anna M, Bond DJ, Honer WG, Lam RW, Yatham LN. Neurocognitive functioning in patients with bipolar I disorder recently recovered from a first manic episode. J Clin Psychiatry. 2010 Sep;71(9):1234-42.

10. Tabarés-Seisdedos R, Balanzá-Martinez V, Sanchez-Moreno J, Martinez-Aran A, Salazar-Fraile J, Selva-Vera G, Rubio C, Mata I, Gómez-Beneyto M, Vieta E. Neurocognitive and clinical predictors of functional outcome in patients with schizophrenia and bipolar I disorder at one-year follow-up. J Affect Disord. 2008 Aug;109(3):286-99.

11. Martino DJ, Marengo E, Igoa A, Scápola M, Ais ED, Perinot L, Strejilevich SA. Neurocognitive and symptomatic predictors of functional outcome in bipolar 
disorders: a prospective 1 year follow-up study. J Affect Disord. 2009 Jul;116(12):37-42.

12. Bonnin CM, Martinez-Arán A, Torrent C, Pacchiarotti I, Rosa AR, Franco C, Murru A, Sanchez-Moreno J, Vieta E. Clinical and neurocognitive predictors of functional outcome in bipolar euthymic patients: a long-term, follow-up study. J Affect Disord. 2010 Feb;121(1-2):156-60

13. Forcada I, Mur M, Mora E, Vieta E, Bartrés-Faz D, Portella MJ. The influence of cognitive reserve on psychosocial and neuropsychological functioning in bipolar disorder. Eur Neuropsychopharmacol. 2015 Feb;25(2):214-22

14. Alberich S, Barbeito S, González-Ortega I, Ugarte A, Vega P, de Azúa SR, López P, Zorrilla I, González-Pinto A. Psychometric properties and validation of a four-item version of the Strauss-Carpenter scale in bipolar disorder. Int J Bipolar Disord. 2016 Dec;4(1):22

15. Mur M, Portella MJ, Martinez-Aran A, Pifarre J, Vieta E. Influence of clinical and neuropsychological variables on the psychosocial and occupational outcome of remitted bipolar patients. Psychopathology. 2009;42(3):148-56.

16. Tohen M, Hennen J, Zarate CM Jr, Baldessarini RJ, Strakowski SM, Stoll AL, Faedda GL, Suppes T, Gebre-Medhin P, Cohen BM Two-year syndromal and functional recovery in 219 cases of first-episode major affective disorder with psychotic features. Am J Psychiatry. 2000 Feb;157(2):220-8.

17. Jaeger J, Vieta E. Functional outcome and disability in bipolar disorders: ongoing research and future directions. Bipolar Disord. 2007 Feb-Mar;9(1-2):1-2.

18. González-Ortega I, Alberich S, Echeburúa E, Aizpuru F, Millán E, Vieta E, Matute C, González-Pinto A. Subclinical depressive symptoms and continued cannabis use: predictors of negative outcomes in first episode psychosis. PLoS One. 2015 Apr 15;10(4):e0123707.

19. Torrent C, Bonnin Cdel M, Martinez-Arán A, Valle J, Amann BL, González-Pinto A, Crespo JM, Ibáñez Á, Garcia-Portilla MP, Tabarés-Seisdedos R, Arango C, Colom F, Solé B, Pacchiarotti I, Rosa AR, Ayuso-Mateos JL, Anaya C, Fernández P, Landín-Romero R, Alonso-Lana S, Ortiz-Gil J, Segura B, Barbeito S, Vega P, Fernández M, Ugarte A, Subirà M, Cerrillo E, Custal N, Menchón JM, Saiz-Ruiz J, Rodao JM, Isella S, Alegría A, Al-Halabi S, Bobes J, Galván G, Saiz PA, BalanzáMartinez V, Selva G, Fuentes-Durá I, Correa P, Mayoral M, Chiclana G, MerchanNaranjo J, Rapado-Castro M, Salamero M, Vieta E. Efficacy of functional 
remediation in bipolar disorder: a multicenter randomized controlled study. Am J Psychiatry. 2013 Aug;170(8):852-9.

20. Bonnin CM, Torrent C, Arango C, Amann BL, Solé B, González-Pinto A, Crespo JM, Tabarés-Seisdedos R, Reinares M, Ayuso-Mateos JL, García-Portilla MP, Ibañez Á, Salamero M, Vieta E, Martinez-Aran A; CIBERSAM Functional Remediation Group. Functional remediation in bipolar disorder: 1-year follow-up of neurocognitive and functional outcome. Br J Psychiatry. 2016 Jan;208(1):87-93.

21. Young, R,C,, Biggs, J.T., Ziegler, V.E., Meyer, D.A., 1978. A rating scale for mania: reliability, validity and sensitivity. Br J Psychiat. 133:429-35

22. Colom,F., Vieta,E., Martinez-Aran,A., Garcia-Garcia,M., Reinares,M., Torrent,C., Goikolea,J.M., Banus,S. and Salamero,M., 2002. [Spanish version of a scale for the assessment of mania: validity and reliability of the Young Mania Rating Scale]. Med Clin (Barc ). 119, 366-371.

23. Hamilton,M., 1960. A rating scale for depression. J Neurol Neurosurg Psychiatry. 23, 56-62.

24. Ramos-Brieva,J.A. and Cordero,V.A., 1986. [Validation of the Castillian version of the Hamilton Rating Scale for Depression]. Actas Luso Esp Neurol Psiquiatr Cienc Afines. 14, 324-334

25. Rosa AR, Sanchez-Moreno J, Martinez-Aran A, Salamero M, Torrent C, Reinares M, Comes M, Colom F, Van Riel W, Ayuso-Mateos JL, Kapczinski F, Vieta E. Validity and reliability of the Functioning Assessment Short Test (FAST) in bipolar disorder. Clin Pract Epidemiol Ment Health. 2007 Jun 7;3:5.

26. MacQueen GM, Young LT, Robb JC et al. Effect of number of episodes on wellbeing and functioning of patients with bipolar disorder. Acta Psychiatr Scand 2000;101:374-381.

27. Fekih-Romdhane F, Homri W, Mrabet A, Labbane R. Factors predicting functioning in type 1 bipolar patients during remission period. Pan Afr Med J. 2016 Oct 3;25:66

28. Arvilommi P, Suominen K, Mantere O, Valtonen H, Leppämäki S, Isometsä E. Predictors of long-term work disability among patients with type I and II bipolar disorder: a prospective 18-month follow-up study. Bipolar Disord. 2015 Dec;17(8):821-35.

29. González-Pinto A, Barbeito S, Alonso M, Alberich S, Haidar MK, Vieta E, TabarésSeisdedos R, Zorrilla I, González-Pinto MA, López P Poor long-term prognosis in 
mixed bipolar patients: 10-year outcomes in the Vitoria prospective naturalistic study in Spain. J Clin Psychiatry. 2011 May;72(5):671-6.

30. Parellada M, Gomez-Vallejo S, Burdeus M, Arango C. Developmental Differences Between Schizophrenia and Bipolar Disorder. Schizophr Bull. 2017 Oct 21;43(6):1176-1189

31. Martin EA, Öngür D, Cohen BM, Lewandowski KE. Social functioning and age across affective and nonaffective psychoses. J Nerv Ment Dis. 2015 Jan;203(1):3742.

32. Reinares M, Papachristou E, Harvey P, Mar Bonnín C, Sánchez-Moreno J, Torrent C, Ayuso-Mateos JL, Ploubidis GB, Vieta E, Frangou S. Towards a clinical staging for bipolar disorder: defining patient subtypes based on functional outcome. J Affect Disord. 2013 Jan 10;144(1-2):65-71

33. Amoretti S, Bernardo M, Bonnin CM, Bioque M, Cabrera B, Mezquida G, Solé B, Vieta $\mathrm{E}$, Torrent $\mathrm{C}$. The impact of cognitive reserve in the outcome of first-episode psychoses: 2-year follow-up study. Eur Neuropsychopharmacol. 2016 Oct;26(10):1638-48

34. Grande I, Sanchez-Moreno J, Sole B, Jimenez E, Torrent C, Bonnin CM, Varo C, Tabares-Seisdedos R, Balanzá-Martinez V, Valls E, Morilla I, Carvalho AF, AyusoMateos JE, Vieta E, Martinez-Aran A. High cognitive reserve in bipolar disorders as a moderator of neurocognitive impairment. J Affect Disord. 2017 Jan 15;208:621627

35. Jiménez E, Solé B, Arias B, Mitjans M, Varo C, Reinares M, Bonnín CDM, Ruíz V, Saiz PA, García-Portilla MP, Burón P, Bobes J, Amann BL, Martínez-Arán A, Torrent C, Vieta E, Benabarre A. Impact of childhood trauma on cognitive profile in bipolar disorder. Bipolar Disord. 2017 Aug;19(5):363-374.

36. Leeson VC, Barnes TR, Hutton SB, Ron MA, Joyce EM. IQ as a predictor of functional outcome in schizophrenia: a longitudinal, four-year study of first-episode psychosis. Schizophr Res. 2009 Jan;107(1):55-60.

37. Grande I, Goikolea JM, de Dios C, González-Pinto A, Montes JM, Saiz-Ruiz J, Prieto E, Vieta E; PREBIS group. Occupational disability in bipolar disorder: analysis of predictors of being on severe disablement benefit (PREBIS study data). Acta Psychiatr Scand. 2013 May;127(5):403-11. 
38. Gutiérrez-Rojas L, Jurado D, Gurpegui M. Factors associated with work, social life and family life disability in bipolar disorder patients. Psychiatry Res. 2011 Apr 30;186(2-3):254-60.

39. Bonnin CM, Torrent C, Goikolea JM, Reinares M, Solé B, Valentí M, SanchezMoreno J, Hidalgo D, Tabarés-Seisdedos R, Martinez-Arán A, Vieta E. The impact of repeated manic episodes and executive dysfunction on work adjustment in bipolar disorder. Eur Arch Psychiatry Clin Neurosci. 2014 Apr;264(3):247-54.

40. Schoeyen HK, Melle I, Sundet K, Aminoff SR, Hellvin T, Auestad BH, Morken G, Andreassen OA. Occupational outcome in bipolar disorder is not predicted by premorbid functioning and intelligence. Bipolar Disord. 2013 May;15(3):294-305.

41. MacQueen GM, Young LT, Joffe RT. A review of psychosocial outcome in patients with bipolar disorder. Acta Psychiatr Scand 2001;103:163-170

42. Rosa AR, Bonnin CM, Vazquez GH, et al. Functional impairment in bipolar II disorder: is it as disabling as bipolar I? J Affect Disord 2010 Dec;127(1-3):71-6

43. Hellvin T, Sundet K, Aminoff SR, Andreassen OA, Melle I. Social functioning in first contact mania: clinical and neurocognitive correlates. Compr Psychiatry. 2013 Jul;54(5):432-8

44. Bonnin CM, Reinares M, Hidalgo-Mazzei D, Undurraga J, Mur M, Sáez C, Nieto E, Vázquez GH, Balanzá-Martinez V, Tabarés-Seisdedos R, Vieta E. Predictors of functional outcome after a manic episode. J Affect Disord. 2015 Aug 15;182:121-5.

45. Tohen M, Zarate CA, Jr., Hennen J et al. The McLean-Harvard First-Episode Mania Study: prediction of recovery and first recurrence. Am J Psychiatry 2003;160:20992107

46. Gitlin MJ, Miklowitz DJ. The difficult lives of individuals with bipolar disorder: A review of functional outcomes and their implications for treatment. J Affect Disord. 2017 Feb;209:147-154.

47. Cavanagh JT, Van Beck M, Muir W, Blackwood DH Case-control study of neurocognitive function in euthymic patients with bipolar disorder: an association with mania. Br J Psychiatry. 2002 Apr;180:320-6.

48. Kapczinski F, Vieta E, Andreazza AC, Frey BN, Gomes FA, Tramontina J, KauerSant'anna M, Grassi-Oliveira R, Post RM. Allostatic load in bipolar disorder: implications for pathophysiology and treatment. Neurosci Biobehav Rev. 2008;32(4):675-92 
49. Kapczinski F, Dias VV, Kauer-Sant'Anna M, Frey BN, Grassi-Oliveira R, Colom F, Berk M. Clinical implications of a staging model for bipolar disorders. Expert Rev Neurother. 2009 Jul;9(7):957-66

50. Wingo AP, Baldessarini RJ, Holtzheimer PE, Harvey PD. Factors associated with functional recovery in bipolar disorder patients. Bipolar Disord. 2010 May;12(3):319-26.

51. López-Jaramillo C, Lopera-Vásquez J, Gallo A, Ospina-Duque J, Bell V, Torrent C, Martinez-Arán A, Vieta E. Effects of recurrence on the cognitive performance of patients with bipolar I disorder: implications for relapse prevention and treatment adherence. Bipolar Disord. 2010 Aug;12(5):557-67.

52. Martino DJ, Igoa A, Marengo E, Scápola M, Strejilevich SA. Longitudinal relationship between clinical course and neurocognitive impairments in bipolar disorder. J Affect Disord. 2018 Jan 1;225:250-255.

53. Rosa AR, González-Ortega I, González-Pinto A, Echeburúa E, Comes M, MartínezÀran A, Ugarte A, Fernández M, Vieta E. One-year psychosocial functioning in patients in the early vs. late stage of bipolar disorder. Acta Psychiatr Scand. 2012 Apr;125(4):335-41

54. Solé B, Bonnin CM, Mayoral M, Amann BL, Torres I, González-Pinto A, Jimenez E, Crespo JM, Colom F, Tabarés-Seisdedos R, Reinares M, Ayuso-Mateos JL, Soria S, Garcia-Portilla MP, Ibañez Á, Vieta E, Martinez-Aran A, Torrent C; CIBERSAM Functional Remediation Group. Functional remediation for patients with bipolar II disorder: improvement of functioning and subsyndromal symptoms. Eur Neuropsychopharmacol. 2015 Feb;25(2):257-64.

55. Garriga M, Solé E, González-Pinto A, Selva-Vera G, Arranz B, Amann BL, SaizRuiz J, Pérez-Blanco J, Vieta E. Efficacy of quetiapine XR vs. placebo as concomitant treatment to mood stabilizers in the control of subthreshold symptoms of bipolar disorder: Results from a pilot, randomized controlled trial. Eur Neuropsychopharmacol. 2017 Oct;27(10):959-969

56. Weinstock,L.M. and Miller,I.W., 2008. Functional impairment as a predictor of short-term symptom course in bipolar I disorder. Bipolar Disord. 10, 437-442.

57. Samalin L, de Chazeron I, Vieta E, Bellivier F, Llorca PM. Residual symptoms and specific functional impairments in euthymic patients with bipolar disorder. Bipolar Disord. 2016 Mar;18(2):164-73 
58. Gitlin MJ, Swendsen J, Heller TL, Hammen C. Relapse and impairment in bipolar disorder. Am J Psychiatry. 1995 Nov;152(11):1635-40.

59. Pallaskorpi S, Suominen K, Ketokivi M, Mantere O, Arvilommi P, Valtonen H, Leppämäki S, Isometsä E. Five-year outcome of bipolar I and II disorders: findings of the Jorvi Bipolar Study. Bipolar Disord. 2015 Jun;17(4):363-74.

60. Deckersbach,T., Nierenberg,A.A., Kessler,R., Lund,H.G., Ametrano,R.M., Sachs,G., Rauch,S.L. and Dougherty,D., 2010. RESEARCH: Cognitive rehabilitation for bipolar disorder: An open trial for employed patients with residual depressive symptoms. CNS Neurosci Ther. 16, 298-307.

61. Novo P, Landin-Romero R, Radua J, Vicens V, Fernandez I, Garcia F, PomarolClotet E, McKenna PJ, Shapiro F, Amann BL. Eye movement desensitization and reprocessing therapy in subsyndromal bipolar patients with a history of traumatic events: a randomized, controlled pilot-study. Psychiatry Res. 2014 Sep 30;219(1):122-8

62. Sanchez-Moreno J, Bonnin C, González-Pinto A, Amann BL, Solé B, BalanzáMartinez V, Arango C, Jimenez E, Tabarés-Seisdedos R, Garcia-Portilla MP, Ibáñez A, Crespo JM, Ayuso-Mateos JL, Vieta E, Martinez-Aran A, Torrent C; CIBERSAM Functional Remediation Group. Do patients with bipolar disorder and subsyndromal symptoms benefit from functional remediation? A 12-month followup study. Eur Neuropsychopharmacol. 2017 Apr;27(4):350-359.

63. Solé B, Jiménez E, Torrent C, Del Mar Bonnin C, Torres I, Reinares M, Priego Á, Salamero M, Colom F, Varo C, Vieta E, Martinez-Arán A. Cognitive variability in bipolar II disorder: who is cognitively impaired and who is preserved. Bipolar Disord. 2016 May;18(3):288-99.

64. Jensen JH, Knorr U, Vinberg M, Kessing LV, Miskowiak KW. Discrete neurocognitive subgroups in fully or partially remitted bipolar disorder: Associations with functional abilities. J Affect Disord. 2016 Nov 15;205:378-386.

65. Zyto S, Jabben N, Schulte PF, Regeer BJ, Kupka RW. A pilot study of a combined group and individual functional remediation program for patients with bipolar I disorder. J Affect Disord. 2016 Apr;194:9-15.

66. Lewandowski KE, Sperry SH, Cohen BM, Norris LA, Fitzmaurice GM, Ongur D, Keshavan MS. Treatment to Enhance Cognition in Bipolar Disorder (TREC-BD): Efficacy of a Randomized Controlled Trial of Cognitive Remediation Versus Active 
Control. J Clin Psychiatry. 2017 Oct 17. pii: 17m11476. doi:

10.4088/JCP.17m11476. [Epub ahead of print]

67. Veeh J, Kopf J, Kittel-Schneider S, Deckert J, Reif A. Cognitive remediation for bipolar patients with objective cognitive impairment: a naturalistic study. Int $\mathrm{J}$ Bipolar Disord. 2017 Dec;5(1):8. doi: 10.1186/s40345-017-0079-3. Epub 2017 Apr 13.

68. Miskowiak KW, Ehrenreich H, Christensen EM, Kessing LV, Vinberg M. Recombinant human erythropoietin to target cognitive dysfunction in bipolar disorder: a double-blind, randomized, placebo-controlled phase 2 trial.J Clin Psychiatry. 2014 Dec;75(12):1347-55. doi:

69. Yatham LN, Mackala S, Basivireddy J, Ahn S, Walji N, Hu C, Lam RW, Torres IJ. Lurasidone versus treatment as usual for cognitive impairment in euthymic patients with bipolar I disorder: a randomised, open-label, pilot study. Lancet Psychiatry. 2017 Mar;4(3):208-21

70. Demant KM, Vinberg M, Kessing LV, Miskowiak KW. Effects of Short-Term Cognitive Remediation on Cognitive Dysfunction in Partially or Fully Remitted Individuals with Bipolar Disorder: Results of a Randomised Controlled Trial. PLoS One. 2015 Jun 12;10(6):e0127955.

71. Solé B, Jiménez E, Torrent C, Reinares M, Bonnin CDM, Torres I, Varo C, Grande I, Valls E, Salagre E, Sanchez-Moreno J, Martinez-Aran A, Carvalho AF, Vieta E. Cognitive Impairment in Bipolar Disorder: Treatment and Prevention Strategies. Int J Neuropsychopharmacol. 2017 Aug 1;20(8):670-680.

72. Bonnin CM, Torrent C, Vieta E, Martinez-Arán A. Restoring functioning in bipolar disorder: functional remediation. Harv Rev Psychiatry. 2014 Nov-Dec;22(6):326-30

73. Sanchez-Moreno J, Martinez-Aran A, Vieta E. Treatment of Functional Impairment in Patients with Bipolar Disorder. Curr Psychiatry Rep. 2017 Jan;19(1):3.

74. Vieta E, Salagre E, Grande I, Carvalho A, Fernandes B, Berk M, Birmaher B, Tohen M, Suppes T. Early intervention in bipolar disorder. Am J Psychiatry, in press. 


\section{University Library}

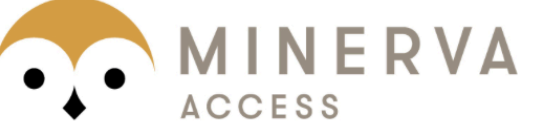

A gateway to Melbourne's research publications

Minerva Access is the Institutional Repository of The University of Melbourne

\section{Author/s:}

Sanchez-Moreno, J;Bonnin, CM;Gonzalez-Pinto, A;Amann, BL;Sole, B;Balanza-Martinez, V;Arango, C;Jimenez, E;Tabares-Seisdedos, R;Garcia-Portilla, MP;lbanez, A;Crespo, JM;Ayuso-Mateos, JL;Martinez-Aran, A;Torrent, C;Vieta, E

Title:

Factors associated with poor functional outcome in bipolar disorder: sociodemographic, clinical, and neurocognitive variables

Date:

2018-08-01

\section{Citation:}

Sanchez-Moreno, J., Bonnin, C. M., Gonzalez-Pinto, A., Amann, B. L., Sole, B., BalanzaMartinez, V., Arango, C., Jimenez, E., Tabares-Seisdedos, R., Garcia-Portilla, M. P., Ibanez, A., Crespo, J. M., Ayuso-Mateos, J. L., Martinez-Aran, A., Torrent, C. \& Vieta, E. (2018). Factors associated with poor functional outcome in bipolar disorder: sociodemographic, clinical, and neurocognitive variables. ACTA PSYCHIATRICA SCANDINAVICA, 138 (2), pp.145-154. https://doi.org/10.1111/acps. 12894.

Persistent Link:

http://hdl.handle.net/11343/284322 